\title{
Adsorption of Crystal Violet onto an Agricultural Waste Residue: Kinetics, Isotherm, Thermodynamics, and Mechanism of Adsorption
}

\author{
Ilyasse Loulidi (iD, ${ }^{1}$ Fatima Boukhlifi, ${ }^{1}$ Mbarka Ouchabi, ${ }^{2}$ Abdelouahed Amar, ${ }^{1}$ Maria Jabri, \\ Abderahim Kali, ${ }^{1}$ Salma Chraibi, ${ }^{1}$ Chaimaa Hadey, ${ }^{3}$ and Faissal Aziz ${ }^{4}$ \\ ${ }^{1}$ Laboratory of Chemistry and Biology Applied to the Environment, Faculty of Sciences, Moulay Ismail University, \\ BP 11201-Zitoune, Meknes, Morocco \\ ${ }^{2}$ Laboratory of Catalysis and Corrosion of Materials, Chouaïb Doukkali University, Faculty of Sciences El Jadida, BP. 20, \\ El Jadida, Morocco \\ ${ }^{3}$ Engineering Sciences and Trades Laboratory, ENSAM, University Moulay Ismail, Meknes, Morocco \\ ${ }^{4}$ National Centre for Research and Study on Water and Energy (CNEREE), Cadi Ayyad University, Marrakech, Morocco \\ Correspondence should be addressed to Ilyasse Loulidi; il.loulidi@gmail.com
}

Received 13 September 2019; Revised 18 March 2020; Accepted 4 April 2020; Published 1 May 2020

Academic Editor: Qiquan Wang

Copyright (C) 2020 Ilyasse Loulidi et al. This is an open access article distributed under the Creative Commons Attribution License, which permits unrestricted use, distribution, and reproduction in any medium, provided the original work is properly cited.

\begin{abstract}
Agricultural waste can be exploited for the adsorption of dyes, due to their low cost, availability, cost-effectiveness, and efficiency. In this study, we were interested in the elimination of crystal violet dye, from aqueous solutions, by adsorption on almond shellbased material, as a low-cost and ecofriendly adsorbent. The almond shells were first analyzed by Fourier transform infrared spectroscopy (FTIR) and X-ray diffraction; then, the influence of adsorbent dose, initial dye concentration time, and $\mathrm{pH}$ were studied to assess adsorption capacity under optimal experimental conditions. Experimental results indicate that almond shell adsorbent removes about $83 \%$ of the dye from the solutions at room temperature and in batch mode; the kinetic study showed that the equilibrium time is about $90 \mathrm{~min}$, and the model of pseudo-second order could very well describe adsorption kinetics. The modulation of adsorption isotherms showed that retention follows the Langmuir model. The thermodynamic study has shown that the adsorption is endothermic $\left(\Delta H^{\circ}>0\right)$ and spontaneous $\left(\Delta G^{\circ}<0\right)$.
\end{abstract}

\section{Introduction}

Many industries, such as the textile, plastics, and paper, use dyes to hue their products, and large volumes of water are consumed. Consequently, they generate a considerable quantity of colored wastewaters. More than 100000 dyes available in the trade with more than $710^{5} \mathrm{t}$ of dyes are produced annually in the world [1]. $1000 \mathrm{t}$ of these dyes are released annually into the aquatic system [2].

The dye is the first pollutant to be detected in wastewater [3]. The presence of a very low concentration of dyes, in water, is very noticeable and undesirable. Several treatment methods were used for treating effluents containing dyes $[2,4]$. But these differ in their effectiveness, cost, and environmental impact [5]. Adsorption is the most effective technique widely used $[6,7]$, in which activated carbon is the most frequently used adsorbent in the purification of water. The high cost required by adsorption using activated carbon [2] pushes researchers to find other alternatives such as waste or agricultural by-products [4]. Agricultural waste consists mainly of cellulose, hemicellulose, and lignin, which are effective adsorbents for a wide range of pollutants because of their richness in functional groups such as hydroxyl groups, carboxyl, and phenols [8]. Other advantages that make them as excellent candidates are the capacity and the rate of adsorption, the high selectivity for different pollutants, and also rapid kinetics [4]. Agricultural waste is better than other adsorbents, as they are generally used without or with minimal treatment (washing, drying, and grinding) [9]. Several recent studies have used various agricultural wastes 
for adsorption of dyes in effluents. Table 1 shows some examples.

Almond is the fruit of almond tree, which is the second most important fruit species cultivated in Morocco after the olive tree, with a production of 101,000 t/year in 2016, which is the equivalent of 80,000 tonnes of almond shells, according to data from the Moroccan Federation of Almond Tree Producers. These residues are discarded as solid waste, which poses environmental problems. It is therefore necessary to find an appropriate method to solve the disposal problem. The use of this inexpensive material as an adsorbent contributes to the solution to this problem and to the application of the principle of "self-cleaning of waste."

Crystal violet is widely used as a violet dye in the textile industry for dyeing cotton and silk. It is also used in the manufacture of paints and printing inks [10]. Crystal violet is carcinogenic and has been classified as a recalcitrant molecule because it is poorly metabolized by microbes, is nonbiodegradable, and can persist in various environments. It is highly toxic to the cells [11].

The purpose of this research paper is to investigate the potential use of almond shells to remove the crystal violet dye from aqueous solutions. Adsorption parameters including dye concentration, contact time, almond shell dose, and $\mathrm{pH}$ were studied to determine the effectiveness of the adsorbent. The characterization of the adsorbent before and after adsorption was achieved in order to identify the mechanism governing the fixation of the dye molecules on the adsorbent.

\section{Materials and Methods}

2.1. Adsorbent Preparation. The almond shells (AS) were washed, dried for 24 hours at a temperature of $110^{\circ} \mathrm{C}$ in an oven, and then crushed and sieved to obtain fine and homogeneous samples $(<0.2 \mathrm{~mm})$.

2.2. Adsorbate Preparation. Crystal violet (CV) (characteristics given in Table 2) dye was used as the adsorbate. A stock solution of crystal violet $(1 \mathrm{~g} / \mathrm{L})$ was first prepared by dissolving a known quantity in deionized water. The stock solution was finally diluted to obtain the desired concentration.

2.3. Adsorption Study. All adsorption experiments were realized at room temperature $\left(\approx 25^{\circ} \mathrm{C}\right)$ and in the batch mode. A mass of the adsorbent was contacted with a volume $V=40 \mathrm{ml}$ of the initial crystal violet solution $C_{0}$. The assembly was agitated for a time $t$ of adsorption, and then, the solid was separated from the solution by filtration on a microporous filter. The absorbance of the supernatant solution was measured using a UV-vis spectrophotometer at the wavelength corresponding to the maximum absorbance $\left(\lambda_{\max }=590 \mathrm{~nm}\right)$. The concentration at time $t\left(C_{t}\right)$ of the dye in the mixture was calculated using a calibration curve prepared from the known concentrations of the CV. The removal percentage $\left(R_{t}(\%)\right)$ of the $\mathrm{CV}$ and the quantity adsorbed to the surface of the AS $\left(q_{t}(\mathrm{mg} / \mathrm{g})\right)$ were determined using the following equations [23]:

$$
\begin{gathered}
R_{t}=\frac{\left(C_{0}-C_{t}\right) \cdot 100}{C_{0}}, \\
q_{t}=\frac{\left(C_{0}-C_{t}\right) \cdot V}{m},
\end{gathered}
$$

where $C_{0}$ and $C_{t}$ are the $\mathrm{CV}$ initial and final concentration $(\mathrm{mg} / \mathrm{L})$ at time $t, V$ is the solution volume $(\mathrm{L})$, and $m$ is the adsorbent mass (g).

\section{Results and Discussion}

3.1. X-Ray Diffraction Analysis. Figure 1 shows the diffractograms of the AS before and after adsorption of the dye. It can be seen on the one hand that the two diffractograms are identical which means that the material undergoes no modification after adsorption, and on the other hand, the broadband at about $22^{\circ}$ justifies certain crystalline phases in the material. In fact, lignocellulosic materials present defects of structures offering the possibility of obtaining monocrystals called whiskers [24].

\subsection{Fourier Transform Infrared (FTIR) Spectroscopy.} FTIR spectroscopy is a widely used method for determining the functional groups that serve as adsorption sites. Figure 2 shows the FTIR spectra of the AS before and after CV adsorption. The analysis of the FTIR spectrum shows the presence of many peaks in the range of wavenumbers from 4,000 to $500 \mathrm{~cm}^{-1}$, which highlights the complex nature of the material analyzed. Before adsorption, the broad band at about $3420 \mathrm{~cm}^{-1}$ corresponds to the elongation of the $\mathrm{O}-\mathrm{H}$ groups, the band at $2910 \mathrm{~cm}^{-1}$ relates to the elongation of the $\mathrm{C}-\mathrm{H}$ group, and the band at 1740 corresponds to the elongation vibration of the nonconjugated $\mathrm{C}=\mathrm{O}$ bonds; these vibrations are mainly due to the ester and carboxylic acid functions present in the lignin, pectin, and hemicelluloses; the $1640 \mathrm{~cm}^{-1}$ band is characteristic for the elongation of the $\mathrm{C}=\mathrm{C}$ bonds of aromatic compounds, and the $1045 \mathrm{~cm}^{-1}$ band is characteristic of the deformation in the $\mathrm{C}-\mathrm{O}$ plane of aromatic compounds and acetyl and carboxylic acid functions. After adsorption of the dye, the intensity of the bands decreased significantly and the band of elongation of the $\mathrm{O}-\mathrm{H}$ widens, indicating the presence of interactions between the AS and CV functional groups.

\subsection{Effect of Physicochemical Parameters on Dye Removal Efficiency}

3.3.1. Effect of Contact Time. It is necessary to obtain the time at the end of which the adsorption equilibrium is reached. This study was conducted for concentrations of $25 \mathrm{mg} / \mathrm{L}$ and $50 \mathrm{mg} / \mathrm{L}$. The results obtained are shown in Figure 3(a), which illustrate the evolution of the adsorbed quantity over time. From the figure, we can see that the equilibrium is reached almost at the end of 90 minutes. The results show the existence of two phases: the first rapid and 
TABLE 1: Adsorption capacities of some natural adsorbents for dye removal.

\begin{tabular}{lccc}
\hline Adsorbents & Dye & Adsorption capacities $\left(\mathrm{mg} \mathrm{g}^{-1}\right)$ & References \\
\hline Neem bark & Malachite green & 0.36 & {$[12]$} \\
Tamarind shell & Congo red & 10.48 & 18.53 \\
Grape fruit peel & Reactive blue 19 & 13.99 & {$[13]$} \\
Peanut hull & Sunset yellow & 1.6 & {$[15]$} \\
Coir pith & Acid violet & 4.42 & {$[16]$} \\
Banana pith & Acid brilliant blue & 19.88 & {$[17]$} \\
Orange peel & Acid violet 17 & 18.2 & {$[18]$} \\
Banana peel & Congo red & 4.6 & {$[19]$} \\
Corncob & Dye mixture & 33.55 & {$[20]$} \\
Potato peel & Methylene blue & 16.00 & {$[21]$} \\
Yellow passion fruit & Methylene blue & & \\
\hline
\end{tabular}

TABLE 2: Chemical properties and characteristics of crystal violet.

\begin{tabular}{lc}
\hline Generic name & Crystal violet \\
\hline Chemical formula & $\mathrm{C}_{25} \mathrm{H}_{30} \mathrm{~N}_{3} \mathrm{Cl}$ \\
Molecular weight (g/ & 407.98 \\
mol) & Cationic \\
Type of dye & $590 \mathrm{~nm}$ \\
$\lambda_{\max }(\mathrm{nm})$ &
\end{tabular}

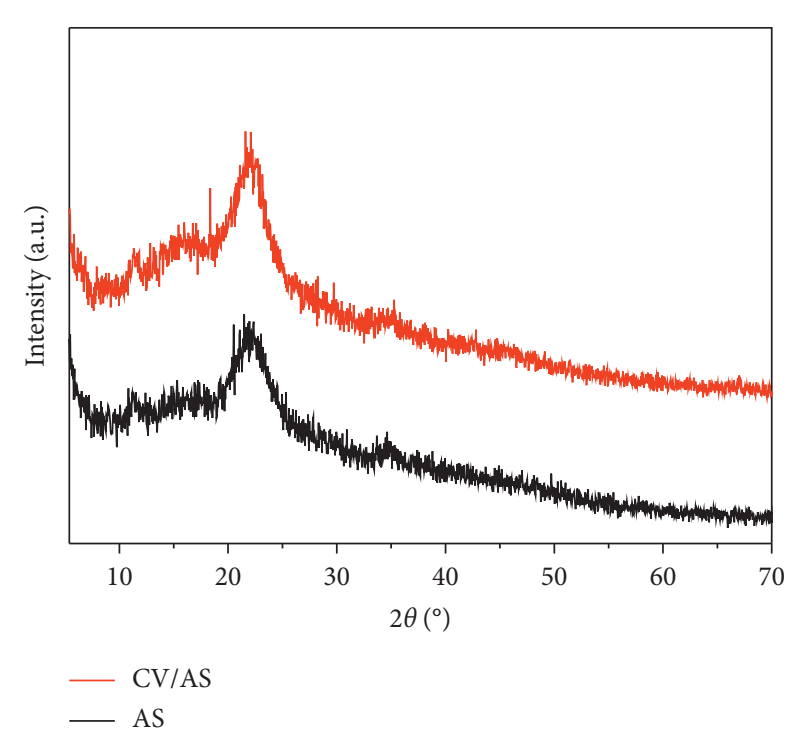

FIGURE 1: X-ray diffraction spectra of almond shell before (AS) and after adsorption (CV/AS).

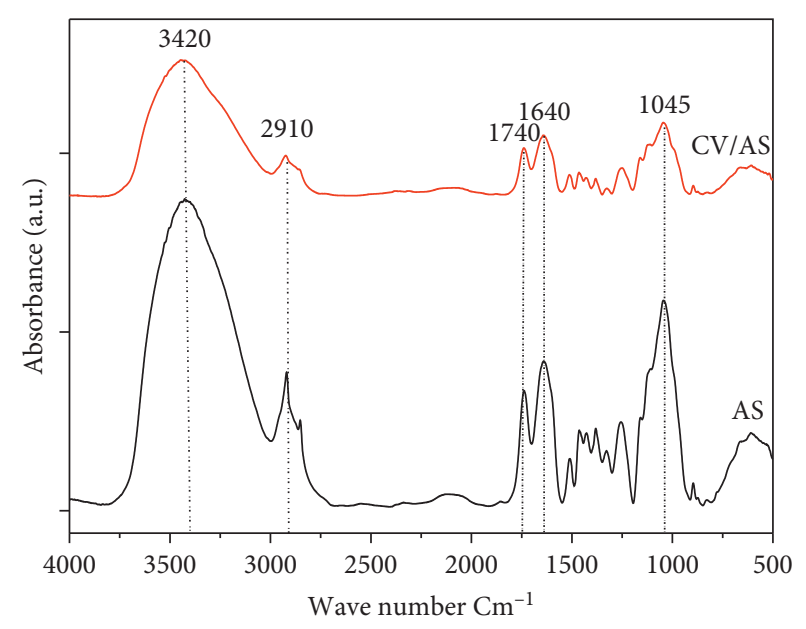

FIGURE 2: FTIR spectra of almond shell before (AS) and after CV adsorption (CV/AS).

the second slow. This is related to the high availability of the adsorbent-free active sites at the beginning of the experiment, which decrease as the adsorption progresses. These curves also show that the fixed quantity $q_{t}$ increases with $C_{0}$. The curve of $C_{0}=25 \mathrm{mg} / \mathrm{L}$ is lower than that of $C_{0}=50 \mathrm{mg} / \mathrm{L}$.

3.3.2. Effect of Initial Crystal Violet Concentration. For this study, the initial concentration was varied in the range of $20 \mathrm{mg} / \mathrm{L}$ to $100 \mathrm{mg} / \mathrm{L}$ by maintaining the adsorbent dose at $5 \mathrm{~g} / \mathrm{L}$, the temperature at $20^{\circ} \mathrm{C}$, and the $\mathrm{pH}$ at 6 . The results are shown in Figure 3(b). It can be observed that the CV elimination rate decreases from $84 \%$ to $49 \%$ when the initial $\mathrm{CV}$ concentration varies from 20 to $200 \mathrm{mg} / \mathrm{L}$. The decrease in the removal rate is probably due to the increase in the number of $\mathrm{CV}$ ions in the solution for the same number of sites and the same adsorbent surface area.

3.3.3. Effect of the Initial $\mathrm{pH}$ of the Solution. $\mathrm{pH}$ is a critical parameter to be taken into account when removing dyes from aqueous solutions, as it can affect the charge on the surface of the adsorbent. The zero charge point $\mathrm{pH}_{\mathrm{pzc}}$ of AS was 4.7 (inset in Figure 3(c)). The percentage of $\mathrm{CV}$ 


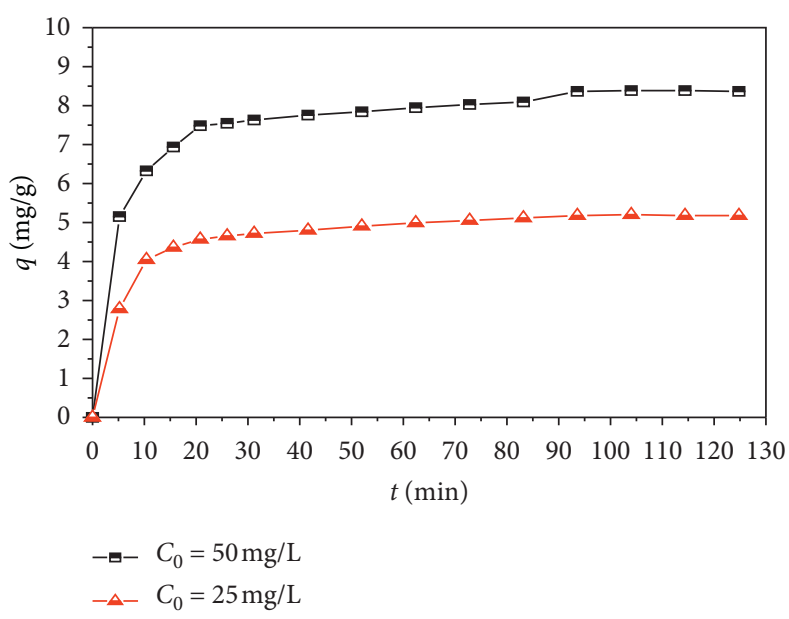

(a)

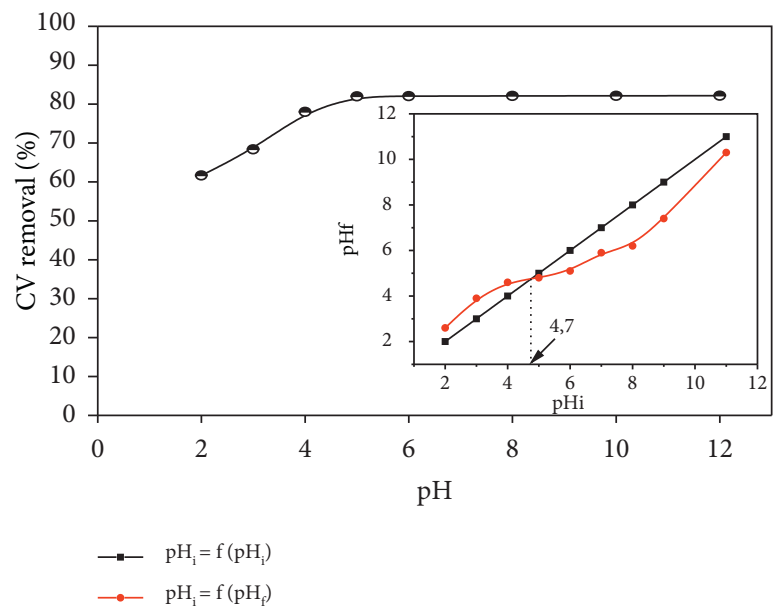

(c)

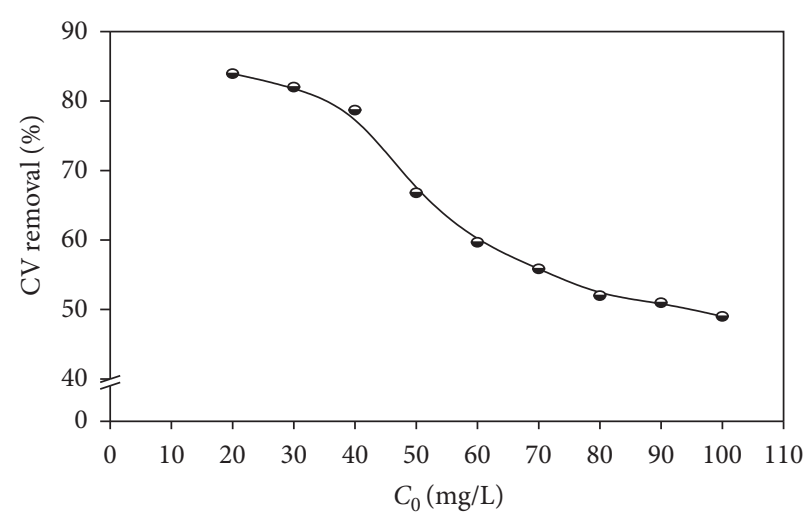

(b)

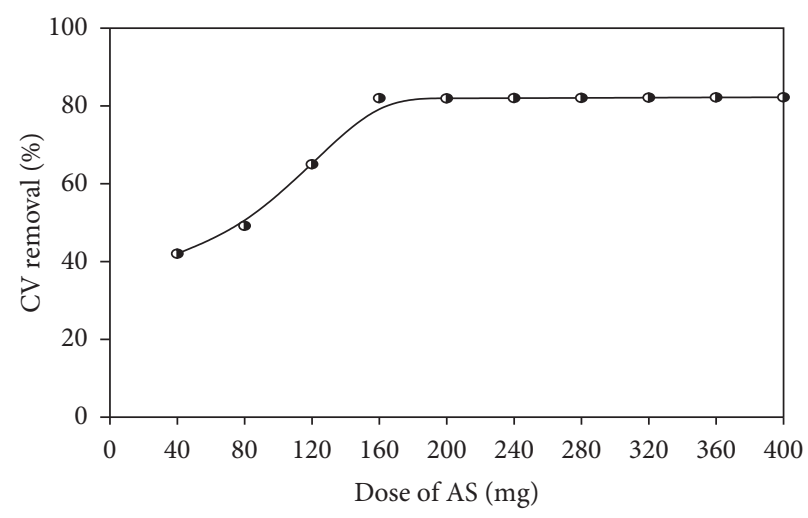

(d)

FIGURE 3: Effect of (a) contact time on adsorption; (b) initial dye concentration on adsorption; (c) pH on CV adsorption; (d) the adsorbent dose on adsorption process. The inset represents the $\mathrm{pH}$ variation in terms of the initial $\mathrm{pH}$ of the solution to determine the point of zero charge $\mathrm{pH}_{\mathrm{pzc}}$.

removal by the AS at different $\mathrm{pH}$ values was then studied, while keeping the other parameters at constant values. The results show that the highest removal efficiency of the $\mathrm{CV}$ (82\%) was observed in the $\mathrm{pH}$ range of 6-12. This efficiency decreased to $62 \%$ at a $\mathrm{pH}$ of 2 . Indeed, at $\mathrm{pH}>\mathrm{pH}_{\mathrm{pzc}}$, the surface of the AS is negatively charged, and this charge increases proportionally to the $\mathrm{pH}$. Therefore, removal efficiency increases when the $\mathrm{pH}$ is in the range of 3-6 due to attractive forces occurring between the cationic dye and the negatively charged surface. Consequently, the optimal $\mathrm{pH}$ value that maximizes the removal of dye from the aqueous solution is 6 .

3.3.4. Effect of Adsorbent's Dose. CV adsorption on AS was studied by varying the dose of the adsorbent from 40 to $400 \mathrm{mg}$ for a concentration of $30 \mathrm{mg} / \mathrm{L}$ of $\mathrm{CV}$ and a $\mathrm{pH}=6$. According to Figure 3(d), it can be seen that CV removal has increased rapidly from $42 \%$ to $82 \%$ in the range of $40-200 \mathrm{mg}$ SA and remains constant in the range of $200 \mathrm{mg}-400 \mathrm{mg}$; this is due to the increase in the contact surface, thus establishing the equilibrium. The adsorbent dose was set at $200 \mathrm{mg}$ for the subsequent experiments.

3.4. Adsorption Equilibrium Study. The adsorption isotherm is the curve binding, at a fixed temperature, the quantity of product adsorbed per initial mass of adsorbent at the concentration residual in the solution after adsorption equilibrium. It was used to determine the maximum adsorption capacity and the type of interaction between the CV and AS. To exploit the data from the CV adsorption isotherm by AS, the Langmuir and Freundlich equations in their linear form were used. The linear form of the Langmuir isotherm is indicated in the following equation:

$$
\frac{C_{e}}{q_{e}}=\frac{1}{K_{L} \cdot Q_{m}}+\frac{C_{e}}{Q_{m}} .
$$

The linear form of the Freundlich isotherm is indicated in the following equation: 


$$
\operatorname{Ln} q_{e}=\operatorname{Ln} K_{F}+\frac{1}{n} \operatorname{Ln} C_{e},
$$

where $C_{e}(\mathrm{mg} / \mathrm{L})$ is the equilibrium concentration; $Q_{e}(\mathrm{mg} / \mathrm{g})$ is the equilibrium adsorbed quantity; $Q_{m}(\mathrm{mg} / \mathrm{g})$ is the maximum adsorption capacity; $K_{L}(\mathrm{~L} / \mathrm{mg})$ is the Langmuir constant; and $K_{F}$ and $n$ are the Freundlich constants.

The representations of the Langmuir and Freundlich models are given in Figure 4, and the equilibrium parameters obtained are shown in Table 3.

The value of the correlation coefficient $\left(R^{2}\right)$ for the Langmuir isotherm is higher than that of the Freundlich isotherm; this means that the Langmuir model better represents the adsorption process of CV by the AS. This suggests that CV fixation is done in monolayer, without interaction between the adsorbed molecules, on energetically equivalent sites. In addition to that, the $R_{L}$ value is less than 1 which indicates that the adsorption of the dye is favorable.

3.5. Adsorption Kinetics. In order to model the adsorption kinetics, the kinetic models of the pseudo-first order and pseudo-second order were used. The expression of the pseudo-first-order model is in the form cited by Lagergren (5) $[25]:$

$$
\operatorname{Ln}\left(q_{e}-q_{t}\right)=\operatorname{Ln} q_{e}-K_{1} t .
$$

The expression of the pseudo-second-order model is in the form cited by Ho and Mckay (6) [26]:

$$
\frac{t}{q_{t}}=\frac{1}{K_{2} q_{e}^{2}}+\frac{1}{q_{e}} t
$$

where $q_{t}\left(\mathrm{mg} \cdot \mathrm{g}^{-1}\right)$ and $q_{e}\left(\mathrm{mg} \cdot \mathrm{g}^{-1}\right)$ are the adsorbed quantity of dye at time $t$ and at equilibrium and $k_{1}\left(\mathrm{~min}^{-1}\right)$ and $k_{2}$ $\left(\mathrm{g} \cdot \mathrm{mg}^{-1} \cdot \mathrm{min}\right)$ are the constants of pseudo-first-order and pseudo-second-order models, respectively.

The curves of both models are shown in Figure 5, and the constants obtained from the different models are recapitulated in Table 4.

From the $R^{2}$ values reported in Table 4 , it can be deduced that the pseudo-second-order model is the one that best describes the $\mathrm{CV}$ adsorption process on AS. We also observe that the adsorbed quantities calculated by this model are closer to those determined experimentally.

\subsection{Effect of Temperature and Thermodynamics of Adsorption.}

The thermodynamic study was conducted at $25,30,40$, and $50^{\circ} \mathrm{C}$. The tests were performed on $40 \mathrm{ml}$ mixtures of dye solutions at a concentration of $30 \mathrm{mg} \cdot \mathrm{L}^{-1}$, with $160 \mathrm{mg}$ masses of AS in $100 \mathrm{~mL}$ flasks. These mixtures were maintained at constant agitation of $200 \mathrm{rpm}^{-1}$ for a time of 4 hours. Figure 6(a) shows the influence of temperature on the dye retention rate. From the figure, we notice that this rate increases with increasing temperature, suggesting that the process is endothermic, and that increasing temperature promotes its progress.

Thermodynamic parameters such as standard Gibbs free energy change $\left(\Delta G^{\circ}\right)$, standard enthalpy change $\left(\Delta H^{\circ}\right)$, and standard entropy change $\left(\Delta S^{\circ}\right)$ were determined by using the following equations [25]:

$$
\begin{gathered}
\operatorname{Ln}\left(K_{d}\right)=\frac{\Delta^{S^{\circ}}}{R}-\frac{\Delta^{H^{\circ}}}{R T}, \\
\Delta^{G^{\circ}}=\Delta^{H^{\circ}}-T \Delta^{S^{\circ}},
\end{gathered}
$$

where $K_{d}=q_{e} / C_{e}$ : distribution constant; $R$ : universal gas constant $(8.314 \mathrm{~J} / \mathrm{mol} \mathrm{K})$; and $T$ : absolute temperature $(\mathrm{K})$.

Table 5 gives the values of standard Gibbs free energy change $\left(\Delta G^{\circ}\right)$, standard enthalpy change $\left(\Delta H^{\circ}\right)$, and standard entropy change $\left(\Delta S^{\circ}\right)$, extrapolated from the plot $\ln \left(K_{d}\right) v s 1 /$ $T$ (Figure 6(b)). The positive value of $\Delta H^{\circ}$ shows that the adsorption process of the CV on AS is endothermic and that it is indeed a physisorption $\left(<40 \mathrm{~kJ} \cdot \mathrm{mol}^{-1}\right)$ [27].

The negative values of $\Delta G^{\circ}$ indicate that the adsorption is spontaneous while the positive value of $\Delta S^{\circ}$ indicates the increase in randomness at the solid-liquid interface during sorption. This is the normal consequence of the phenomenon of physical sorption, which occurs through electrostatic interactions. Similar results were obtained during the adsorption of malachite green by almond gum [28] as well as the adsorption of methylene blue by garlic straw [29].

3.7. Adsorption Mechanism. To understand the adsorption mechanism, it is necessary to examine the structure of the adsorbate and the properties of the adsorbent surface. For this purpose, it should be noted that CV is a cationic dye with amine groups in its structure and in aqueous medium dissociates into $\mathrm{CV}^{+}$and $\mathrm{Cl}^{-}$[30]. On the other hand, $\mathrm{AS}$ is a lignocellulosic material consisting of cellulose, hemicellulose, and lignin and other minor constituents [31, 32]. Cellulose and hemicellulose contain the majority of functional groupa, such as hydroxyl and carboxyl (confirmed by the FTIR spectrum), while lignin is a complex, systematically polymerized, and highly aromatic substance and acts as a cementing matrix that is maintained between and in both cellulose and hemicellulose units. In this study, the removal of CV by AS adsorption is highly pH dependent (Figure 3(c)). The CV has been adequately adsorbed for $\mathrm{pH} \geq 5$.

Based on the experimental results of this study, and depending on the structure of the adsorbate and the properties of the adsorbent surface, the mechanism for removing CV by AS adsorption involves the following steps:

(i) Migration of the dye from the solution to the surface of the adsorbent

(ii) Dye diffusion through the boundary layer on the surface of the adsorbent

(iii) Adsorption of the dye on the AS surface, which can be due to two mechanisms

The first mechanism can explain the phenomenon of adsorption by the formation of hydrogen bonds between the surface hydroxyl and carboxyl groups and the nitrogen atoms of the CV as suggested in Figure 7.

The second mechanism is a dye-hydrogen ion exchange mechanism because at $\mathrm{pH} \geq 5$, the surface functional groups 


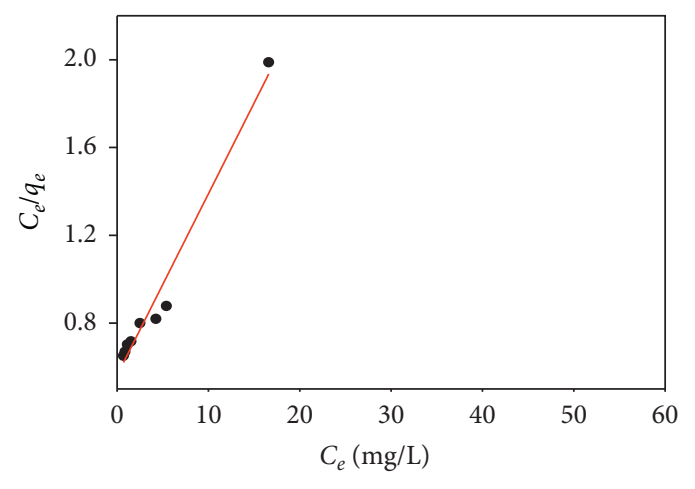

(a)

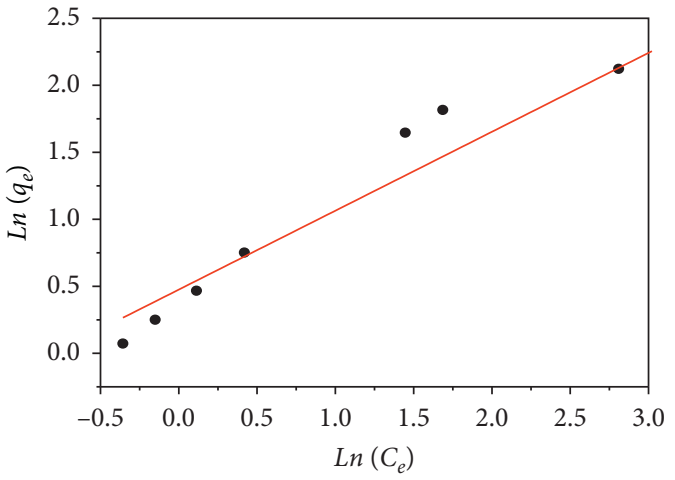

(b)

FIgURE 4: Adsorption isotherms of CV at the surface of AS: (a) Langmuir isotherms; (b) Freundlich isotherms.

TABLE 3: Isotherm parameters for CV removal by AS.

\begin{tabular}{lccccc}
\hline Langmuir isotherm parameters & \multicolumn{5}{c}{ Freundlich isotherm parameters } \\
\hline $\begin{array}{l}Q_{m}(\mathrm{cal} .) \\
\left(\mathrm{mg}^{-1}\right)\end{array}$ & $R^{2}$ & $K_{L}\left(\mathrm{~L} \cdot \mathrm{mg}^{-1}\right)$ & $R_{L}$ & $K_{\mathrm{f}}\left(\mathrm{L} \cdot \mathrm{g}^{-1}\right)$ & $n$ \\
12.2 & 0.987 & 0.146 & 0.064 & 1.64 & 1.70 \\
\hline
\end{tabular}

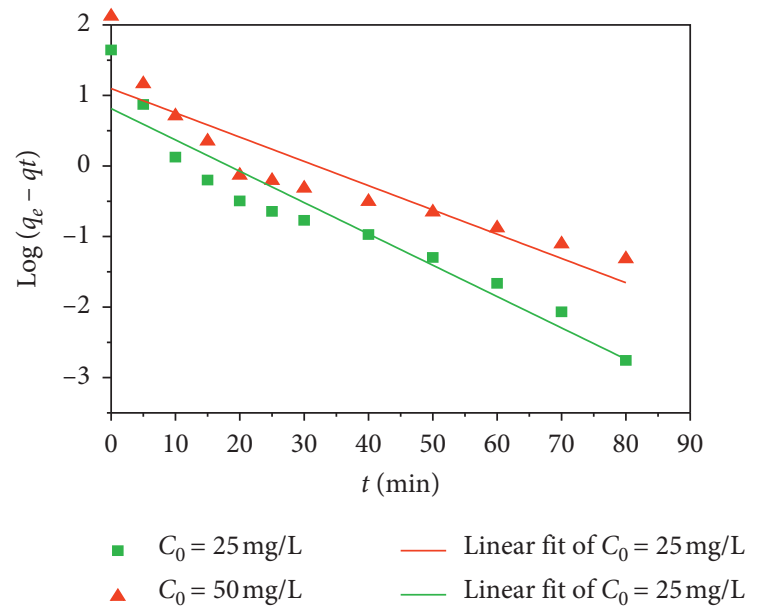

(a)

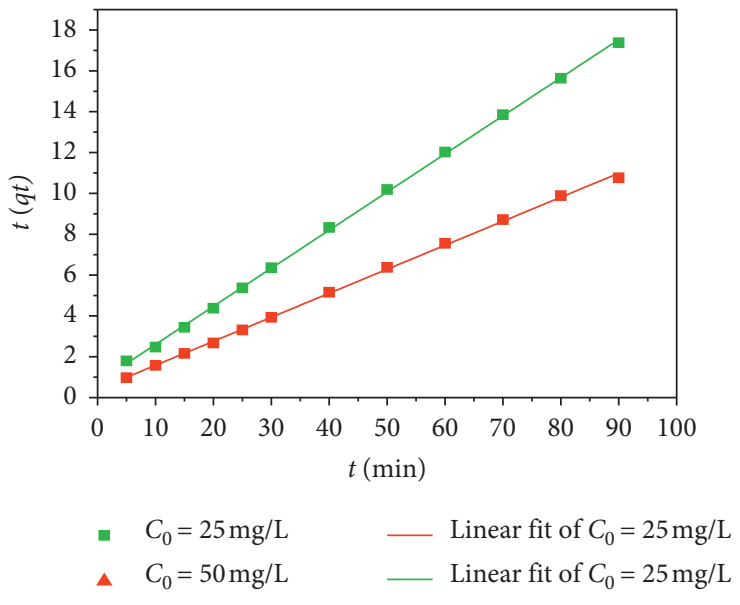

(b)

FIgURE 5: Kinetic adsorption of CV at the surface of AS: (a) pseudo-first-order kinetics; (b) Pseudo-second-order kinetics.

Table 4: Pseudo-first-order and pseudo-second-order adsorption rate constants for the different initial CV concentrations $\left(C_{0}\right)$.

\begin{tabular}{lccccr}
\hline$C_{0}(\mathrm{mg} / \mathrm{L})$ & \multicolumn{3}{c}{ Pseudo-first-order kinetic } & \multicolumn{2}{c}{ Pseudo-second-order kinetic } \\
& $q_{1}(\mathrm{mg} / \mathrm{g})$ & $K_{1}\left(\mathrm{~min}^{-1}\right)$ & $R^{2}$ & $q_{2}(\mathrm{mg} / \mathrm{g})$ & $K_{2}\left(\mathrm{~g} \cdot \mathrm{mg}^{-1} \mathrm{~min}^{-1}\right)$ \\
\hline 25 & 2.2557 & 0.04441 & 0.95606 & 5.3596 & 0.0471 \\
50 & 2.9961 & 0.0344 & 0.90404 & 8.5048 & 0.3399 \\
\hline
\end{tabular}




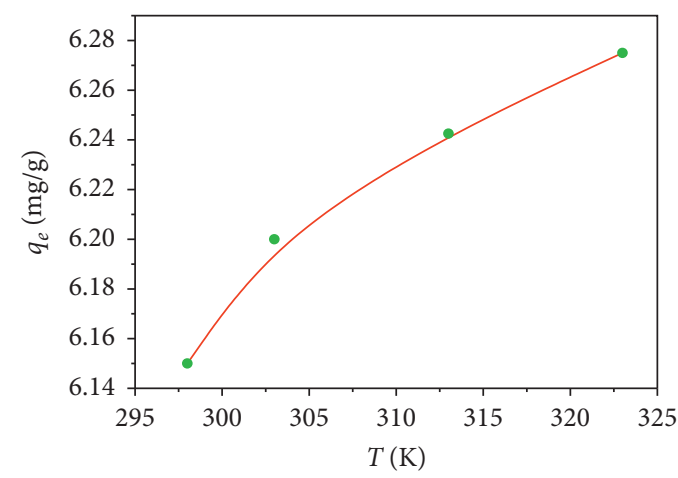

(a)

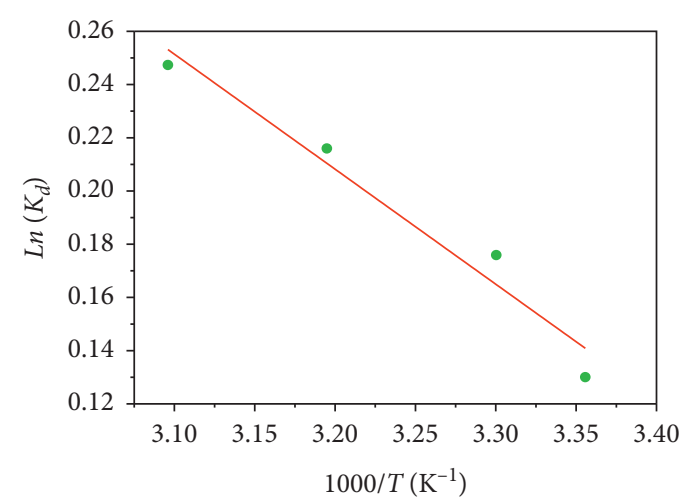

(b)

Figure 6: (a) Effect of temperature on malachite crystal violet rate; (b) plot $\ln \left(K_{d}\right) v s$ 1/Tfor crystal violet adsorption into the almond shell.

TABLE 5: Thermodynamic parameters for adsorption of crystal violet.

\begin{tabular}{lccc}
\hline Température $(\mathrm{K})$ & $\Delta H^{\circ}\left(\mathrm{kJ} \cdot \mathrm{mol}^{-1}\right)$ & $\Delta S^{\circ}\left(\mathrm{J} \cdot \mathrm{mol}^{-1} \cdot \mathrm{K}^{-1}\right)$ & $\Delta G^{\circ}\left(\mathrm{J} \cdot \mathrm{mol}^{-1}\right)$ \\
\hline 298 & & & -349.54 \\
303 & 3.593 & 13.230 & -415.69 \\
313 & & & -547.99 \\
323 & & -680.29 & 0.980 \\
\hline
\end{tabular}

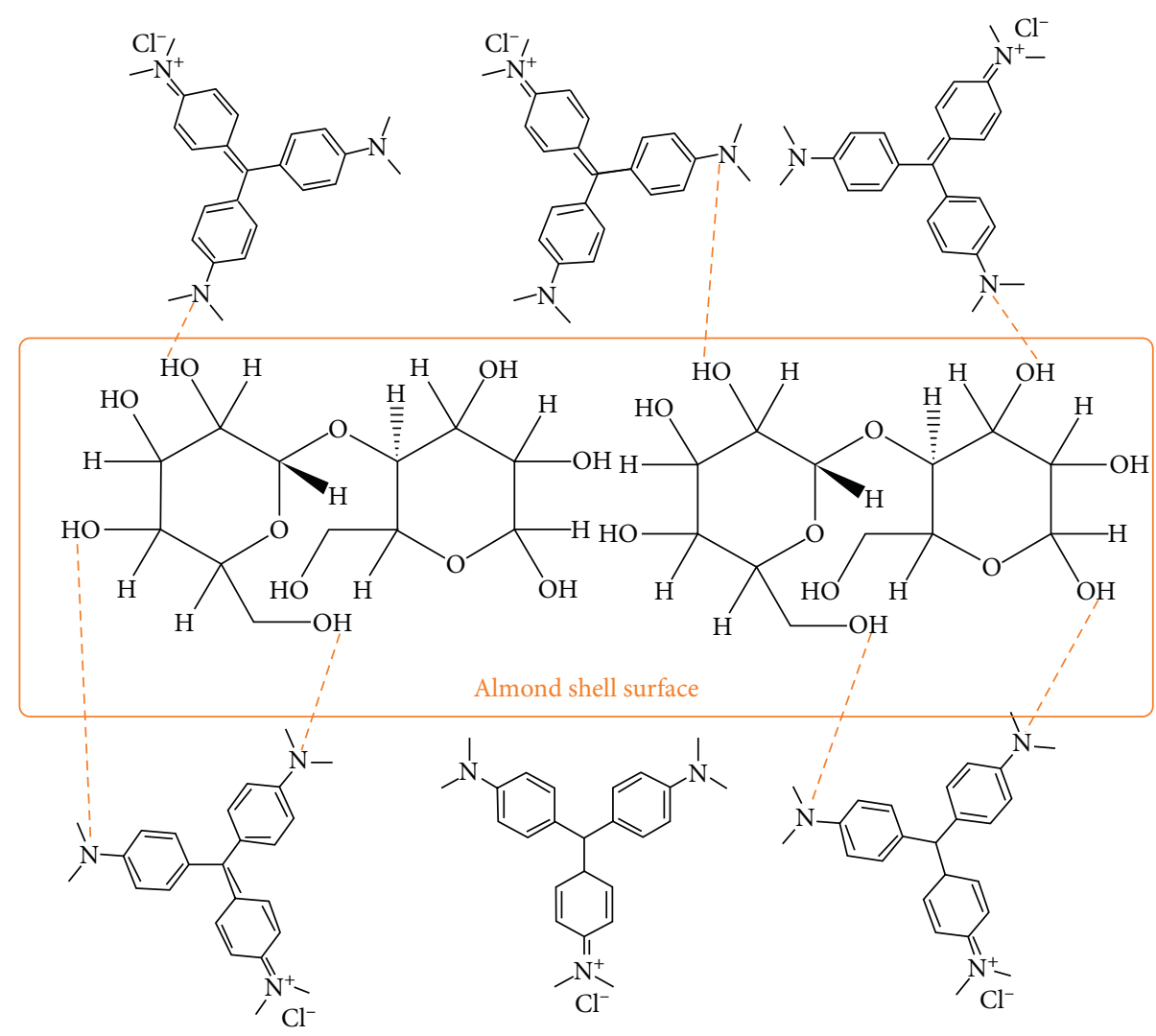

- - - Hydrogen Bonding

FIGURE 7: Schematic representation of hydrogen bonding between nitrogen atoms of CV and hydroxyl groups on the almond shell surface. 


\section{$\mathrm{AS}-\mathrm{COOH} \rightleftharpoons \mathrm{AS}-\mathrm{COO}^{-}+\mathrm{H}^{+}$ \\ $\mathrm{AS}-\mathrm{COO}^{-}+\mathrm{CV}^{+} \rightleftharpoons \mathrm{AS}-\mathrm{COOCV}$}

FIGURE 8: Schematic representation of dye-hydrogen ion exchange mechanism.

are deprotonated and become negatively charged, which facilitates their binding to the positively charged CV molecules, as shown in Figure 8.

\section{Conclusion}

The almond shell, a low-cost and easily available material, has proven to be highly effective to remove crystal violet from aqueous solutions. The equilibrium data were analyzed using Langmuir and Freundlich isotherm models. The maximum monolayer adsorption capacity was equal to $12.2 \mathrm{mg} / \mathrm{g}$. The experimental data of the adsorption isotherm follow the Langmuir model and the pseudo-second-order kinetic model. This work clearly shows that the elimination of crystal violet by the almond shell is feasible, efficient, and economical. Moreover, the almond shell is a promising candidate for wastewater treatment.

\section{Data Availability}

No data were used to support this study.

\section{Conflicts of Interest}

The authors declare that they have no conflicts of interest.

\section{References}

[1] V. K. Garg, R. Kumar, and R. Gupta, "Removal of malachite green dye from aqueous solution by adsorption using agroindustry waste: a case study of Prosopis cineraria," Dyes and Pigments, vol. 62, no. 1, pp. 1-10, 2004.

[2] P. Velmurugan, V. Rathina Kumar, and G. Dhinakaran, "Dye removal from aqueoussolution using low cost adsorbent," International Journal of Environmental Research and Public Health, vol. 1, pp. 7-14, 2011.

[3] I. M. Banat, P. Nigam, D. Singh, and R. Marchant, "Microbial decolorization of textile-dyecontaining effluents: a review," Bioresource Technology, vol. 58, no. 3, pp. 217-227, 1996.

[4] G. Crini, "Non-conventional low-cost adsorbents for dye removal: a review," Bioresource Technology, vol. 97, no. 9, pp. 1061-1085, 2006.

[5] S. Chakraborty, S. Chowdhury, and P. Das Saha, "Adsorption of Crystal Violet from aqueous solution onto $\mathrm{NaOH}$-modified rice husk," Carbohydrate Polymers, vol. 86, no. 4, pp. 15331541, 2011.

[6] A. K. Jain, V. K. Gupta, A. Bhatnagar, and Suhas, "Utilization of industrial waste products as adsorbents for the removal of dyes," Journal of Hazardous Materials, vol. 101, no. 1, pp. 31-42, Jul. 2003.

[7] Y. S. Ho and G. McKay, "Sorption of dyes and copper ions onto biosorbents," Process Biochemistry, vol. 38, no. 7, pp. 1047-1061, Feb. 2003.
[8] B. K. T. F. Hassanein, "Evaluation of ad-sorption potential of the agricultural waste wheat straw for Basic Yellow 21," J. Univ. Chem. Technol. Metall.vol. 45, pp. 407-414, 2010.

[9] A. S. Franca, L. S. Oliveira, and M. E. Ferreira, "Kinetics and equilibrium studies of methylene blue adsorption by spent coffee grounds," Desalination, vol. 249, no. 1, pp. 267-272, 2009.

[10] A. Mittal, J. Mittal, A. Malviya, D. Kaur, and V. K. Gupta, "Adsorption of hazardous dye crystal violet from wastewater by waste materials," Journal of Colloid and Interface Science, vol. 343 , no. 2, pp. 463-473, 2010.

[11] R. Ahmad, "Studies on adsorption of crystal violet dye from aqueous solution onto coniferous pinus bark powder (CPBP)," Journal of Hazardous Materials, vol. 171, no. 1-3, pp. 767-773, 2009.

[12] R. Srivastava and D. C. Rupainwar, "A comparative evaluation for adsorption of dye on neem bark and mango bark powder," Indian Journal of Chemical Technology, vol. 18, pp. 67-75, 2011.

[13] M. C. S. Reddy, "Removal of direct dye from aqueous solution with an adsorbent made from tamarind fruit shell an agricultural solid waste," Journal of Scientific and Industrial Research, vol. 65, pp. 443-446, 2006.

[14] M. Abassi and N. R. Asl, "Removal of hazardous reactive blue 19 dye from aqueous solution by agricultural waste," Journal of the Iranian Chemical Society, vol. 2, pp. 221-230, 2009.

[15] R. Gong, Y. Ding, M. Li, C. Yang, H. Liu, and Y. Sun, "Utilization of powdered peanut hull as biosorbent for removal of anionic dyes from aqueous solution," Dyes and Pigments, vol. 64, no. 3, pp. 187-192, 2005.

[16] C. Namasivayam, M. Dinesh Kumar, K. Selvi, R. Ashruffunissa Begum, T. Vanathi, and R. T. Yamuna, "'Waste' coir pith-a potential biomass for the treatment of dyeing wastewaters," Biomass and Bioenergy, vol. 21, no. 6, pp. 477-483, 2001.

[17] C. Namasivayam, D. Prabha, and M. Kumutha, "Removal of direct red and acid brilliant blue by adsorption on to banana pith," Bioresource Technology, vol. 64, no. 1, pp. 77-79, 1998.

[18] R. Sivaraj, C. Namasivayam, and K. Kadirvelu, "Orange peel as an adsorbent in the removal of Acid violet 17 (acid dye) from aqueous solutions," Waste Management, vol. 21, no. 1, pp. 105-110, 2001.

[19] G. Annadurai, R. Juang, and D. Lee, "Use of cellulose-based wastes for adsorption of dyes from aqueous solutions," Journal of Hazardous Materials, vol. 92, no. 3, pp. 263-274, 2002.

[20] T. Robinson, B. Chandran, and P. Nigam, "Removal of dyes from an artificial textile dye effluent by two agricultural waste residues, corncob and barley husk," Environment International, vol. 28, no. 1-2, pp. 29-33, 2002.

[21] Y. A. Öktem, G. S. Pozan Soylu, and N. Aytan, "The adsorption of Methylene Blue from aqueous solution by using waste potato peels; Equilibrium and kinetic studies," Journal of Scientific and Industrial Research, vol. 71, pp. 817-821, 2012.

[22] F. A. Pavan, Y. Gushikem, A. C. Mazzocato, S. L. P. Dias, and E. C. Lima, "Statistical design of experiments as a tool for optimizing the batch conditions to methylene blue biosorption on yellow passion fruit and Mandarin peels," Dyes and Pigments, vol. 72, no. 2, pp. 256-266, 2007.

[23] M. S. Slimani, H. Ahlafi, H. Moussout, F. Boukhlifi, and O. Zegaoui, "Adsorption of hexavalent chromium and phenol onto bentonite modified with HexaDecylTriMethylAmmonium bromide (HDTMABr)," Journal of Advances in Chemistry, vol. 8, no. 2, pp. 1602-1611, 2012. 
[24] D. Klemm, B. Philipp, T. Heinze, U. Heinze, and W. Wagenknecht, "Application of spectroscopic analysis in cellulose chemistry," in Comprehensive Cellulose Chemistry: Fundaments and Analytical Methods, vol. 1, pp. 181-195, Wiley-VCH, Weinheim, Germany, 2004.

[25] S. Langergren, "About the theory of so-called adsorption of soluble substances," Kungliga Svenska Vetenskapsakademiens Handlingar, vol. 24, pp. 1-39, 1898.

[26] Y. S. Ho and G. McKay, "Sorption of dye from aqueous solution by peat," Chemical Engineering Journal, vol. 70, no. 2, pp. 115-124, 1998.

[27] M. Aazza, H. Ahlafi, H. Moussout, and H. Maghat, "Adsorption of metha-nitrophenol onto alumina and HDTMA modified alumina: kinetic, isotherm and mechanism investigations," Journal of Molecular Liquids, vol. 268, pp. 587-597, 2018.

[28] F. Bouaziz, M. Koubaa, F. Kallel, R. E. Ghorbel, and S. E. Chaabouni, "Adsorptive removal of malachite green from aqueous solutions by almond gum: kinetic study and equilibrium isotherms," International Journal of Biological Macromolecules, vol. 105, pp. 56-65, 2017.

[29] F. Kallel, F. Chaari, F. Bouaziz, F. Bettaieb, R. Ghorbel, and S. E. Chaabouni, "Sorption and desorption characteristics for the removal of a toxic dye, methylene blue from aqueous solution by a low cost agricultural by-product," Journal of Molecular Liquids, vol. 219, pp. 279-288, 2016.

[30] R. Kumar and R. Ahmad, "Biosorption of hazardous crystal violet dye from aqueous solution onto treated ginger waste (TGW)," Desalination, vol. 265, no. 1-3, pp. 112-118, 2011.

[31] H. Jaman, D. Chakraborty, and P. Saha, "A study of the thermodynamics and kinetics of copper adsorption using chemically modified rice husk," Clean-Soil, Air, Water, vol. 37, no. 9, pp. 704-711, 2009.

[32] T. G. Chuah, A. Jumasiah, I. Azni, S. Katayon, and S. Y. Thomas Choong, "Rice husk as a potentially low-cost biosorbent for heavy metal and dye removal: an overview," Desalination, vol. 175, no. 3, pp. 305-316, 2005. 